\title{
Altered Meanings of Home Before and During COVID-19 Pandemic
}

\author{
Meral Gezici Yalçın ${ }^{1}$ (D) · N. Ekrem Düzen²
}

Received: 22 July 2020 / Revised: 15 December 2020 / Accepted: 8 January 2021 /

Published online: 27 January 2021

(c) The Author(s), under exclusive licence to Springer Nature Switzerland AG part of Springer Nature 2021

\begin{abstract}
Home came into focus immediately upon learning that COVID-19 is highly contagious and spread by human contact. Precautions people can take to safeguard themselves included physical distancing, social isolation, and staying at home. Despite phases of loosening or tightening precautions in most parts of the world, home retained its safe space status, almost irrespective of geographical location. Recent studies have shown that safety, security, and familiarity are the most referred positive attributes of home. Challenging this attenuation by scholars, negative or mixed meanings of home were highlighted in literary work and critics. Based on our integrative perspective bringing scientific and literary work together, we argue that pandemic might lead to changes in the meaning of home both in positive and negative directions simultaneously, inducing an ambiguous experience or even engendering a situated ambivalence. In this regard, we retrospectively inquired about the changes in home's meaning in its social, personal, and symbolic attributes. A data set of 66 participants from 15 cities in Turkey revealed that there are not only alterations in the existing connotations of home but also additional ones, in positive, negative, and both directions. Results obtained in the pandemic context were discussed in the light of home studies through a constructionist perspective.
\end{abstract}

Keywords House $\cdot$ Home $\cdot$ Meaning $\cdot$ Pandemic $\cdot$ Culture

\section{Altered Meanings of Home Before and During COVID-19 Pandemic}

The year 2020 was marked by the COVID-19 pandemic with a vocabulary of its own (Appleton, 2020). Among the most frequently articulated phrases like physical distancing and social isolation, stay at home grew into a catchword as it was taken an essential, if not obligatory, strategy in many countries to ward off the detrimental consequences of the pandemic (Medline et al., 2020). Home has promptly turned out to be the central base to keep away from the contagion, at least for people who had a convenience to do so (Saltiel, 2020).

Meral Gezici Yalçın

meralgeziciyalcin@ibu.edu.tr

1 Department of Psychology, Bolu Abant İzzet Baysal University, Bolu, Turkey

2 Institute for Interdisciplinary Research on Conflict and Violence, Bielefeld University, Bielefeld, Germany 
Despite stay at home has been deemed a practical and relatively achievable measure to adopt, it has been revealed soon that not all people find it an accommodating solution, even in the presence of public encouragement and pondered or pledged reinforcements (Bushman, Pelechrinis \& Labrinidis, 2020; Tull et al., 2020). Early representations of drawbacks retarding the efficiency of stay at home strategy included the rate of accomplishment which varied substantially even among neighboring countries. Part of the observed variation is attributable to living in a contact or noncontact culture. In so-called contact cultures individuals face one another more directly, interact closer, touch one another more, look in the eye, and speak in a louder voice than do individuals of the noncontact cultures (see Hall, 1966). In a country like Italy where contact culture is predominant, authorities have had difficulty in implementing regulations to make people stay at home even though a high rate of morbidity and mortality persisted a long while (Bilgin, 2020), whereas in supposedly noncontact cultures such as Germany (for an extensive cross-country analysis, see Sorokowska et al., 2017), people seemed to follow the rules and recommendations more or less voluntarily (see Gokmen, Turen, Erdem \& Tokmak, 2020), at least until the loosening of the precautions (Primc $\&$ Slabe-Erker, 2020).

While regional or cultural differences continue to remain among major considerations affecting the performance of strategies for motivating people to assume their share of responsibility and take personal precautions, we argue that the meaning of home is a significant vigor influencing people's attitudes towards or against complying with the stay at home practice.

In times of widespread peril, behavioral adjustments are expected to adapt to the new situation. Under the pressure of emerging conditions, defensive strategies appear to cope with far-reaching ecological threats (van Bavel, Baicker, Boggio et al., 2020). During COVID-19 pandemic, physical distancing, social isolation, and stay at home emerged among relatively well-received recommendations which were quickly passed the stage of endorsements and raised to the level of social norms (Jetten et al., 2020). It is usual to expect people to conform to these norms in order not to lose personal benefits (keeping safe) and social approval and affiliation (not to be excluded) (Cialdini \& Goldstein, 2004; Wood, 2000). In turn, social norms may lead to substantial behavioral changes in terms of established habits and routines of most people, especially in times of crises.

Our aim in this paper is to connect social and individual entailments of home to interpret better the challenges of COVID-19 era beyond the contagion itself. We propose that examining personal meanings of home could shed light the ways people adapt to new circumstances emerged due to the pandemic. Surprisingly, there is hardly enough research regarding the role and function of home during gravely harmful hazards. Even though home became central to mitigate the potentially devastating effects of COVID-19, it has yet received little scientific attention in its own right, still less by psychologists. On the other hand, literary work seemingly entails significant concern about the place of home in human experience and bears profitable implications for a scientific examination of the meaning of home, at its best, worst, and inbetween. Therefore, since existing research could still provide starting points to examine the meaning of home and since literary work could provide us insight about the relevance of home in everyday life, we choose to benefit from the inputs of the latter, wherever applicable, in understanding the impact of lockdown on the meaning of home, with its tangible and intangible components.

Therefore, we intend to examine how people's attributes of home have changed during the pandemic as compared to their pre-pandemic discernments. We find it useful to take the meaning of home as a composite attribute consisting affective, cognitive, and behavioral components (Boccagni, 2017) in recognizing the alterations of this wholistic 
understanding. Against this background, we resorted to personal narratives, retrospectively comparing depictions of home before and during lockdown.

To this end, we attempted to trace changes in daily life practices before and during the lockdown to understand inconveniences, deprivations, and losses alongside new possibilities emerged by or associated with staying at home. Physically distancing the self from others, hygiene rules categorizing social networks into parts, and newly introduced regulations in public spaces exerted a tremendous burden on people's daily routines which are intensely affecting the homely practices and thus the meaning of home. Additionally, since our study is done in a country of contact culture (Sayan et al., 2013), understanding the alterations in the meaning of home in this perspective may provide implications for subsequent studies which would examine cultural differences in introducing and adopting public health measures including stay at home practices.

We define home as an imaginary space imbued not only with senses of belonging, desire, and intimacy but also with feelings of fear, violence, and alienation. That is, we approach home as a pervasive affect perpetually present in one's cognitive-emotive processing. Since the meaning of home is culturally produced, like that of space and place (Baldwin et al., 1999), it has a shared meaning though liquid in character (Hubbard \& Kitchin, 2010) and bear ambiguities at the level of individual appraisals. In other words, cultural significance of home is marked by variations in individuals' discourses constructed through their daily life experiences (Jackson, 1989) though demonstrating separate and combined features concurrently. Intersectional stratifications like social class, age, and gender (Blunt \& Dowling, 2006; see also Rose, 1995a, b) seem to shape daily practices at home significantly in diversifying or unifying the experience and meaning of it, both across and within.

Being at home is not limited to the daily activities in a house (for the differences between house and home, see Boccagni, 2017; Blunt \& Dowling, 2006), but reaches out to urban spaces (e.g., Lewicka, 2005; see also Prohansky, 1978). Spending time at public places like parks, markets, restaurants, coffee shops, worship sites, entertainment areas, and interacting with people in the neighborhood are crucial elements of attachment, adjustment, and life satisfaction, as well as bridging and bonding, making boundaries or opening spaces for others (e.g., Anton \& Lawrence, 2014; Kyle et al., 2004). Maintaining social relationships, exercising cultural routines and rituals in urban spaces have significant impacts on people's experiences of being and feeling at home (Mandel, 2008). Pivotal to social recognition (Boccagni \& Brighenti, 2015), sense of being at home signals being involved and included and entails having roots in a certain location harboring a web of memories being associated or even identified with it (Bilgin, 2011). Therefore, home, homemaking, homing, and homely feelings (see Boccagni, 2017 for conceptual differences) are crucial provisions for understanding how people adapt themselves to crisis like COVID-19 pandemic and aftermaths.

Home is not only a domestic social zone where intimate relations are developed and materialized but also a social space which is created and recreated through everyday practices (Blunt \& Dowling, 2006) and actively negotiated and constructed by relationships with places and others (Boccagni, 2017; Şenol Cantek et al., 2014). A constellation of institutional (political and historical), ideal (values, memories, expectations), and practical (daily interactions) elements (Brun and Fábos, 2015) as constructed across public, private, and communal urban spaces (Boccagni \& Brighenti, 2015) radiate from house to the globe (Blunt \& Dowling, 2006). There is also inbetween spaces (spaces between buildings and streets such as balconies, courtyards, front yards) where public and the private intersects (Can \& Heath, 2016). 
In this regard, home is not a mere location for spending the daily life, but a locus of social and personal experience where belongingness, identities, and power relations are intersectionally connected. Therefore, home amounts not only to a functional but also symbolic substance beyond its material and practical features (e.g., dwelling) or effective purposes (e.g., shelter, security, safety) (see Boccagni, 2017; Boccagni \& Brighenti, 2015).

Based on the idea that home is the locus of social and personal experience, we argue that "home is an imagined space" (Irannejad, 2018, 36), or an "imagined site" (Woodrow, 2001, 69), i.e., a set of intersecting ideas and feelings associated with safety, comfort, and familiarity (Hage, 1997) across neighborhood, city, and even the nation-state (Goodwin, 2008; Moser \& Uzzell, 2003; Silvey, 2013). It is as well a significant place of acculturation, especially when it comes to interactions between ethnic or socio-cultural groups (Zick, 2010). In a nutshell, home has a shared cultural meaning well beyond a sheer list of everyday practices or daily tasks to be fulfilled inside and out (Blunt \& Dowling, 2006).

In a time of pandemic, new attributes of home may also emerge, owing to actual or potential losses such as control and mastery of homing. Having or not having command over physical or abstract properties of home may appear more critical than they used to be. Home might also be associated with negative connotations such as obligations, responsibilities, coercion, imprisonment, and repression (Gürbilek, 2019, 2020). Conversely, home may gain an emerging positive significance by realizing that it accounts for being protected against disease during the pandemic while bringing about an opportunity to spend time for one's own sake.

Therefore, we argue that people tend to embrace ambiguous images and experience ambivalent feelings even though they continue to adopt culturally congruent attributes of home during the lockdown, be it positive or negative, in order to cope with fears, threats, and normative changes especially when deprived of socializing and denied from public spaces. Accordingly, we aspire to interpret our data on the basis of how such alterations in the image of home is sketched in participants' narratives and what these alterations could possibly tell about the aftermath of the lockdown.

\section{Method}

\section{Participants and Procedure}

A total of 66 participants $(18$ men $)$ aged between 16 and $65\left(M_{\text {age }}=36.12\right.$, sd $\left.=14.90\right)$ occupying 28 households and residing in 15 different cities in Turkey (Ankara, Bartın, Balıkesir, Bolu, Bursa, Çanakkale, Düzce, Elazı̆̆ Istanbul, Kahramanmaraş, Kastamonu, Kayseri, Kocaeli, Mersin, Muğla) participated in the study.

Among the 28 households reached, all but two participants reported that they live with their families. Sixteen of the households were represented by three persons (mostly, parents and a child in late adolescence), six households by two persons (either spouses or one parent and a child), and six households were represented by one person. In other words, each data entry consisted of one to three participants from the same household. Participants reported that they had been living in the same city in varying time lengths (minimum 10, maximum 58 years).

Twenty-nine participants were undergraduate students. Other participants had varied educational degrees ( 9 elementary school, 5 secondary school, 10 high school, 4 college, and 9 graduate). Regarding occupational status, 13 participants (all women) 
indicated that they are domestic workers (7 elementary school, 2 secondary school, and 4 high school). Nineteen people reported that they are workers in different sectors (waitress, cook, nurse, teacher, police, driver, lawyer, etc.), whereas 4 reported retired.

In our qualitative inquiry, all participants were asked to reflect on the meaning of home before and during the lockdown. Attributes of dwelling unit and neighborhood, accounts of daily activities including social relationships, and sentiments associated with both were enquired through open ended questions. Narrations related to the actual lockdown were obtained concurrently whereas those to pre-lockdown, retrospectively. Participants were contacted via social media during the first lockdown, in April 2020. Each participant was invited to an online interview on a voluntary basis.

\section{Data Analysis Preparation}

We used the thematic analysis technique (Braun \& Clarke, 2006, 2013; Hayes, 2010) to analyze the qualitative data obtained in this study. Being a flexible tool, thematic analysis gives researcher a theoretical freedom (Braun \& Clarke, 2006) to use it with different methods. While we wanted to know the changes in the meaning of home, we focused on participants' own interpretations to minimize interfering with their accounts (see Reicher, 2000). That is, we did not take an interrogative stance towards the meanings expressed in the data. Rather, we put the narratives in an organizing framework to interpret what is expressed in the data, i.e., instead of latent level we stayed at semantic level (see Braun \& Clarke, 2006).

Following the idea that themes are "meaningful entities that are constructed from codes that unify disparate data and capture the essence of some degree of recurrent meaning across a data-set" (Braun \& Clarke, 2006, 740; see also DeSantis \& Ugarriza, 2000), we generated our themes by applying both theory-driven (deductive) and datadriven (inductive) processes. We adopted the constructionist epistemological approach, thus focused on the sociocultural contexts and structural conditions through which individual accounts emerge (Braun \& Clarke, 2006).

To reach that end, we executed multiple steps. First, qualitative data were prepared for the analysis (familiarizing with the data which involves reading and re-reading the data, noting down initial ideas). Secondly, index carts were created, and different subjects were noted (generating initial codes). At the third step, similar subjects were gathered under the same theme (searching for themes). These themes were treated as protothemes and labelled as transitionary (reviewing themes). The final themes were emerged after reading the answers given by the participants to open-ended questions several times (defining and naming themes). For a vivid presentation of results, these themes were described along with a number of compelling excerpts.

\section{Results and Discussion}

Thematic analyses showed that participants mentioned multiple themes in their responses. Therefore, themes recounted below represent discrete experiences but may not necessarily correspond individual persons. 


\section{House Versus Home}

Most big cities in Turkey have been facing urban transformation since the beginning of 2000s. This has had tremendous impact on physical attributes of houses as well as architecture and structure of neighborhoods, influencing social life immensely (e.g., Çavdar \& Tan, 2013; Özet, 2019). Since physical attributes of dwelling bear implications concerning social relationships both at home and in the neighborhood (Blunt \& Dowling, 2006), we find it important to report that most of our participants live in recently built apartments either in close suburbs (13 households) or in city centers (13 households), and only two households reside in larger village houses.

More than half of our participants (17 out of 28 households) reported that they live with their families in flats with four rooms and balconies. Others reported to dwell in two to six rooms flats, except for two that were in a gated residential. Arguably, a four room flat with a balcony is a prototypical familial house in middle-class urban Turkey. Balcony is usually regarded a typical and indispensable feature of a house. It is used for many activities and operations inclusive of relaxing, enjoying the view, eating and drinking, socialization with neighbors and friends, hanging the laundry, etc. Şenol Cantek et al. (2014) summarized four main functions of balcony in their qualitative research: a place for socialization, a place for domestic work (cooking, washing, etc.), extension of privacy after decoration, or using for storing things.

Several participants indicated that during the pandemic they continued to meet with their neighbors from balcony to balcony. Three participants living in flats without balcony expressed their wish to have one when asked about a missing feature of their house they count a significant deficiency. Responses also included garden (4) and terrace (2). These inbetween spaces have significant roles in social interaction and homing in Turkey as shown by other research (Can \& Heath, 2016; Şenol Cantek et al., 2014).

In addition to the emphasis on the importance of having a balcony, our participants reported that they wished to have additional rooms, a larger kitchen, a larger house, and a private space. These predilections were mostly related to the crowdedness of households due to pandemic, while the household members who were normally away, such as students, moved back to their family houses because of the lockdown. Such yearnings indicate clearly that structural elements of a house are important for a composite sense of home, as described by Blunt and Dowling (2006, 3) "home is much more than house or household. Whilst house and household are components of home, on their own they do not capture the complex socio-spatial relations and emotions that define home. A house is not necessarily nor automatically a home, and personal relations that constitute home extend beyond those of the household."

Involuntary withdrawal from social interactions was added to appraisals of home in connection with desired physical compartments of home. Getting together with friends (8), family members (sister, son, father) or other familiars (4), guests (3), and relatives (2) were often failed. On the other hand, some were willing to have silence (3) or stay alone (2). Still others would have liked to go out for a walk (2), have fresh air (3), and enjoy crowded vibes (1). In this regard, during pandemic, inbetween spaces such as balconies, gardens, and front yards were valued more in social isolation as these spaces provided people opportunities to interact with others, at times even without caring enough for physical distancing.

These features and attributes were also mentioned in responses when participants asked to reflect on properties making them feel comfortable at home. Such aspects were 
collapsed under the themes of (a) structure of the house (large flat, balcony, private room, a large kitchen, garden, spaciousness and comfort), (b) freedom at home (hanging out freely, dressing casually, loading off the mind, no meddling with one another), (c) roles and responsibilities (little or no housework, little or no cooking, little or no cleaning, fewer obligations), and (d) silence and tranquility. These thematic properties allowed us to discern that the physical properties of house play a significant role on homely feelings and social relationships both within and outside of the dwelling.

Majority of the participants testified either negative emotions (boredom, tension, anxiety, threat, repression, tiredness, helplessness, loneliness) or ambiguous to ambivalent feelings (complicated, bittersweet, safe but concerned, concerned but content) though few participants stated that they felt safe, peaceful, and content during the lockdown.

These findings indicate that home has affective, cognitive, and behavioral denotations experienced in a composite fashion. A house with its physical and social attributes, and facilities it does and does not provide may lead people to feel or not feel homely. The interplay between psychological, social, and physical modes of experiences (Sixsmith, 1986), and of schemes of space (Lefebvre, 1991) may reveal itself more clearly to observation especially during extraordinary times such as pandemic and lockdown. This is what we intend to demonstrate with regard to altered meanings of home as described and discussed below.

\section{Meaning of Home During the Lockdown}

Ambiguities in the image of home submerge especially when a person is away from home, as Stefan Zweig 2009 states impressively that one may feel safe during the daylight, but that sentiment could turn to a pressing mood when one realizes that it is hard to bear with an alien loneliness surfacing while people retire to their homes where a family, a bed, a relaxed night is waiting for them (1928/1980). Walter Benjamin's exclamation is no less affirming: "I never slept on the street in Berlin. I saw sunset and dawn, but between the two I found myself a shelter." (1988, 42). In Nurdan Gürbilek's expressions, too, the gloomy leaks in the sparkling"when we are away from home ... the light radiating from [another] house shine like a sign of everything that the one, alone and in the dark, is deprived off." $(2019,62)$.

Confirming theses literary authors, participants' expressions of positive denotations of home had an element of remote observation as if they monitor their homes from a distance. What they articulated more easily were the positive qualities that gained salience during the lockdown. Home, in this time of trouble, represented trust, peacefulness, safety, security, happiness, fortune, familial ties, health, sharing, shelter, endurance; all with an opportunity for self-reflection, comfort, rest, and entertainment. It came forward a noticeable rather than taken for granted component of life, which does not only bear the virtue of protecting others but also the value of being protected, i.e., kept safe and secure. It is worth noting that the phrase safe and secure (which is, in Turkish, articulated in one word: güvenli) is among the most frequently expressed terms in participants' appraisals of home. Being or keeping safe and secure (güvenli) were repeated habitually by most participants, and sometimes (by 16 participants with overlaps) in the form of an adjective clause: safe and secure/güvenli place, space, area, life, harbor, feeling, and being.

Another frequently repeated word was family (16 times) and can readily signify a broader connotation than a sheer meaning of the word, depending on the sentence structure and 
context. In that sense, family may have one or more references to the following: being with the family, family ties, spending time with family, family environment, feeling like a family, and importance of having a family. There are also a number of sayings that substitute the word itself but practically perform the same function such as the most loved ones, spending time under the same roof, standing by in rough times, and togetherness.

However, not all attributes portraying the meaning of home by the participants have been classified by a positive mark. Many neutral-to-negative connotations as well surfaced alongside. Despite the apparent salience of positively evaluated qualities, home also meant responsibility, obligation, housework, isolation, adaptation to a crowded family life, lack of social life, lack of private space, limitation of mobility, stress, and boredom. Of all the neutral-to-positive attributes, boredom was the most frequently articulated word (5 times). Nevertheless, our participants were clear about the source of their boredom and they expressed it in different contexts: Being bored by overloaded work at home (1), lack of social life (2), feeling like a prison (3), having nothing to do (4), or simply the atmosphere (5). It is not unexpected that some people might have got bored during the lockdown. Gürbilek (2019) have already pointed out, just on the eve of the COVID-19 pandemic, that home is where prosperity and boredom coexist, as it "brings around an imposing tedium along with a bestowal of an inner world." (p. 63).

In participants' accounts, home is represented a place to stay due to an inevitability. One participant (woman, 58 years old, domestic worker) told that "I avoid staying at home as long as I have not to. But I have to stay, because of the virus. Spending time with my mother makes it a bit better." This reminds us Gürbilek's (2020) concept of home as a runaway, a dead-end, a trap. Also, this participant's representation of home reminds us Walter Benjamin's complaint that not having been escaped from home when we are fifteen is hard to compensate; we only realize what we had missed then, much later, (Benjamin, 1928/1980). To some people, however, home could turn to be a safe haven. For example, a participant (woman, 21 years old, undergraduate student) represented home as "a place to escape from the things we are afraid of... a safe harbour."

Apparently, home may retain positive and negative meanings simultaneously, which give rise to an ambivalent sum. A male participant (47, retired) says "Home is a place where I feel myself in safety. I have no social life. Home is a place where I can get bored." Or as another participant (female, 50, domestic worker) wrote "I used to be a home-loving person but this time everything turned upside down. Now, home means missing our loved ones, having to look at the good weather out of window, and it is a gloomy place; yet it is also a reason to thank heaven since we have it." This ambivalent meaning of home was indicated by scholars from scientific community (Düzen \& Gezici Yalçın, 2020) as well as by literary critics. Gürbilek (2020) notes that home could be both secure and uncanny; while being a shelter against outside, home is also a barrier to access the world outside (Gürbilek, 2019).

The composite sense of being at home also bears metaphoric meanings (Blunt \& Dowling, 2006; Gürbilek, 2020). Our participants likened home to a harbor, life, nest, heaven, and also to a prison. Among a variety of analogies, home has likened even to a hotel. Simultaneous presence of positive and negative meanings of home are visible by these metaphors. A participant (woman, 22 years old, undergraduate student), for example, wrote that "home is sometimes a peaceful nest, but other times it is like a prison." 


\section{Meaning of Home Before the Lockdown}

When participants were asked to reflect on the meaning of home before the pandemic, they responded that home meant rest (12) and repose (8), a place to live, a shelter, spending time with or visiting family, convenience, cozy environment. Retrospectively comparing before and the during lockdown times, some participants reported no change in the meaning of home (11) while others told that they did not think of it at all. For example, a participant (male, 45, worker) wrote "I did not think much about home before the pandemic, because I was spending little time at home. I was mostly with my friends." Another (female, 23, undergraduate student) reported that "I was never indulgent or bound to home. And I was not the type goes out frequently. Now, since staying at home is obligatory, not being able to go out is unsettling. But I cannot complain, this is the right thing to do."

Some (18) indicated a change towards negative direction following the pandemic measures. Participants for whom home meant "a place to rest" before the pandemic, now turned out to mean "cooking" (male, 28, graphic designer) or "adopting to lifestyle of parents" (female, 21, undergraduate student). Likewise, the meaning of home as "a place I go to visit my parents when I miss them" turned out to mean "a place where I got bored" (female, 48, domestic worker). Yet another participant (female, 58, domestic worker) stated that "before the pandemic I was more relieved, more social, I had a life outside the house, I was able to go out and hang around with my friends, home was not a burden to me." However, she had a different account for the duration of the lockdown: "In fact, nowadays home means a stricter order like definite hours for meals; besides, everyone is at home and I know what each does; there is a never-ending housework, and this is a hardship."

Only three participants reported clear positive meanings that home has gained after the lockdown. An undergraduate student (female, 24) wrote that "Before the pandemic home meant uneasiness; I was having disagreements with my family even though each is a loved one for me. Probably because of the habits I have developed during my university years, I mean, living on my own hook." About the duration of the lockdown, in contrast, she reported altered sentiments: "Home is a space for sharing with others. However frequently we might disagree, we forgot about it instantly and easily. That is the place I feel the presence of people who protect and defend me."

Many participants' (24) descriptions of alterations in the meanings of home before and during the lockdown may not be readily categorized as positive or negative. Overall, responses indicated not a definite change in the direction but a discernible change in the extent, adding to the sense of home more ambiguity and experience more ambivalence (see Table 1). This feature is articulated by our participants in various ways. Some observed that home performed more than it used to be: "Nowadays home means 'life' to me. School is here, entertainment place is here, you may say everything; this is the place I rest. Home is a whole life concentrated to this house." (female, 53, teacher). Others mentioned additional functions: "Home is a workplace to me, and kitchen is the restaurant. I love my balcony very much. My wife is my colleague, and my house is a center of entertainment." (male, 50, police officer). The expansion of home from concrete to abstract was also noted: "It is a structure previously I made a good use of meeting certain needs but now it has taken over my whole life." (female, 45, domestic worker). "Home to me is a living space embracing everything." (male, 57, teacher). 
Table 1 Alterations in the meaning of home before and during the lockdown

\begin{tabular}{|c|c|c|}
\hline Demographics & Before lockdown & During lockdown \\
\hline $\begin{array}{l}\text { Female, } 45 \text {, domestic } \\
\text { worker }\end{array}$ & $\begin{array}{l}\text { It meant the normal daily life to } \\
\text { me, the usual state of. In a way, } \\
\text { like in a workplace }\end{array}$ & Nowadays it means safety and security \\
\hline $\begin{array}{l}\text { Female, 22, undergraduate } \\
\text { student }\end{array}$ & $\begin{array}{l}\text { Home meant to me a place I } \\
\text { missed a lot; because I live away } \\
\text { from my family (to study) home } \\
\text { was usually associated with a } \\
\text { longing for it }\end{array}$ & $\begin{array}{l}\text { Home is a safe and secure living place. } \\
\text { It means a quiet and peaceful family } \\
\text { environment in to rest and find peace } \\
\text { with my close ones }\end{array}$ \\
\hline Male, 48, worker & $\begin{array}{l}\text { It is a place I can rest after the } \\
\text { work; a place I can spend time } \\
\text { with my spouse and kids }\end{array}$ & $\begin{array}{l}\text { It is a safe harbour and lively nest. A } \\
\text { haven, in it I am together with my } \\
\text { spouse and kids }\end{array}$ \\
\hline Male, 47, waitress & It is place to rest when I got tired & It means strengthening of family ties \\
\hline
\end{tabular}

\section{Conclusion}

Our data shows that during the pandemic, particularly during the lockdown, the boundaries of home expanded tremendously towards inside. Home had to assume a lot more symbolic and metaphorical functions, and thus meanings, than ever. Inward expansion of home in daily life during the lockdown was articulated by both positive and negative expressions. This might be due to social representations of home as a place where certain duties and routines in daily life (see Lefebvre, 2006) are realized in interaction with significant others-either familial or other forms of relationships like partnership or living community, others can also refer to non-residents at home like friends and neighbors.

In this study, we observed that the lockdown brought about unexpected burdens which gave rise to new and uninvited experiences that people were not necessarily well-prepared to confront. In these circumstances, most people who had an opportunity to follow stay at home scheme were compelled to take novel or alternative actions to make home a better base to ward off the threat. We also noted that people adopted culturally congruent attributes of home during the lockdown in order to cope with fears, threats, and normative changes while having to deal with importunate daily routines individually.

Our data shows that people relied on existing and emerging aspects of home interconnectedly, material and immaterial alike, to re-construct the idea of home in order to convert a compulsory adjustment to an agreeable experience. Our participants reported their experiences both in semantic categories and metaphors which are partially in line with previous work (e.g., Blunt \& Dowling, 2006).

When we examine the data and look at it in its entirety, we notice that the meaning of home underwent significant alterations in a number of ways during the lockdown, supporting the view that it has a liquid character (see Hubbard \& Kitchin, 2010). Most importantly, our participants' responses are not to be straightforwardly classified towards conceptual poles of negative or positive. We observe that most responses have implications in both directions at the same moment, not necessarily favoring either poles. In other words, most appraisals of home had inherent but identifiable elements of ambiguity in perception and ambivalence in experience when retrospectively comparing the current moment to prelockdown term. 
We conclude that home is reconstructed by new experiences of people under the circumstances of the lockdown, confirming the notion of home being a symbolic (Boccagni, 2017; Boccagni \& Brighenti, 2015) and imaginary (Irannejad, 2018; Woodrow, 2001) place. Alterations in daily life practices, intersectional subjectivity (Crenshaw, 1990), emotions, habits, and behaviors culminated in an aggregate alteration in experiencing home, which led to alterations in people's idea of home during the lockdown. Such abstractions and the associated discourses (see Lefebvre, 2006) coupled with cultural meanings and sentiments (Blunt \& Dowling, 2006) reshaped homely feelings, especially when deprived of socializing and denied from public spaces. Therefore, even though there may be significant contextual differences of constituting elements, home remains the locus of social and personal experience, formed by a special brand of interrelationship among people and places linked to them. We suggest that home should be further inquired as a culturally (Baldwin et al., 1999) and discursively (Jackson, 1989) produced space, actively negotiated and constantly re-imagined.

\section{Compliance with Ethical Standards}

Conflicts of Interest The authors declare that they have no conflict of interest.

Ethics Approval Ethics approval could not be obtained before the start of the study as the Ethics Commissions were away both in Bolu Abant İzzet Baysal University and Bielefeld University. Given the circumstances, we turned to our colleagues and received their peer consultancy. In addition, we declare that we abide by the Ethics Guidelines of Turkish Psychological Association.

https://www.psikolog.org.tr/tr/files/folder/etik-yonetmeligi-x389.pdf

Consent to Participate Data of this study were collected online. Therefore, informed consents were also obtained online since (a) face to face interviews were not possible due to the lockdown, and (b) the researchers aimed to reach as many participants in different provinces of the country as possible. Verbal informed consent was obtained prior to the interview. No identifying information has been asked, collected, or recorded.

Consent for Publication The authors affirm that participants provided informed consent for publication of excerpts from the interviews.

Availability of Data and Material Data is in Turkish and can be provided when asked for.

\section{References}

Anton, C. E., \& Lawrence, C. (2014). Home is where the heart is: The effect of place of residence on place attachment and community participation. Journal of Environmental Psychology, 40, 451-461.

Appleton, N. S. (2020). The bubble: A new medical and public health vocabulary for COVID-19 times. Retrieved http://somatosphere.net/2020/the-bubble.html/.

Baldwin, E., Longhurst, B., McCracken, S., Ogborn, M., \& Smith, G. (1999). Introducing cultural studies. Harlow: Prentice Hall.

Benjamin, W. (1928/1980). Einbahnstraße. In Gesammelte Schriften, IV. Frankfurt/Main: Shurkamp Verlag. Benjamin, W. (1988). Berliner Chronik. Frankfurt/Main: Suhrkamp Verlag.

Bilgin, N. M. (2020). Tracking covid-19 spread in Italy with mobility data. Available at SSRN 3585921.

Bilgin, N. (2011). Sosyal düşüncede kent kimliği. Ideal Kent, 3, 20-47.

Boccagni, P. (2017). Migration and the search for home: Mapping domestic space in migrants' everyday lives. UK: Palgrave Macmillian.

Boccagni, P., \& Brighenti, A. M. (2015). Immigrants and home in the making: Thresholds of domesticity, commonality and publicness. Journal of Housing and the Built Environment, 32(1), 1-11. 
Blunt, A., \& Dowling, R. (2006). Home. London: Routledge.

Braun, V., \& Clarke, V. (2006). Using thematic analysis in psychology. Qualitative Research in Psychology, 3(2), 77-101.

Braun, V., \& Clarke, V. (2013). Successful qualitative research: A practical guide for beginners. London: Sage.

Brun, C., \& Fábos, A. (2015). Making homes in limbo? A conceptual framework. Refuge: Canada's Journal on Refugees, 31(1), 5-17.

Bushman, K., Pelechrinis, K., \& Labrinidis, A. (2020). Effectiveness and compliance to social distancing during COVID-19. arXiv preprint arXiv 2006.12720.

Can, I., \& Heath, T. (2016). In-between spaces and social interaction: a morphological analysis of Izmir using space syntax. Journal of Housing and the Built Environment, 31, 31-49. https://doi.org/10.1007/ s10901-015-9442-9.

Cialdini, R. B., \& Goldstein, N. J. (2004). Social influence: compliance and conformity. Annual Review of Psychology, 55, 591-621.

Crenshaw, K. (1990). Mapping the margins: Intersectionality, identity politics, and violence against women of color. Stanford. Law. Review, 43, 1241-1299.

Çavdar, A., \& Tan, P. (Eds.). (2013). İstanbul: Müstesna şehrin istisna hali. İstanbul: Sel.

DeSantis, L., \& Ugarriza, D. N. (2000). The concept of theme as used in qualitative nursing research. Western Journal of Nursing Research, 22(3), 351-372.

Düzen, N. E., \& Gezici Yalçın, M. (2020). Yeni deneyimlerin mahali olarak salgın günlerinde ev. Birikim. Retrieved https://www.birikimdergisi.com/guncel/10167/yeni-deneyimlerin-mahali-olarak-salgin-gunlerinde-ev.

Gokmen, Y., Turen, U., Erdem, H., \& Tokmak, İ. (2020). National preferred interpersonal distance curbs the spread of COVID-19: A cross-country analysis. Disaster medicine and public health preparedness, $1-7$.

Goodwin, M. (2008). Homes away from home: The intimate geographies of Earl Buck and Gertrude Stein. NTU Studies in Language and Literature, 19, 117-154.

Gürbilek, N. (2019). Ev ödevi. İstanbul: Metis.

Gürbilek, N. (2020). İkinci hayat: Kaçmak, kovulmak, dönmek üzerine denemeler. İstanbul: Metis.

Hall, E. T. (1966). The hidden dimension. New York: Doubleday.

Hage, G. (1997). At home in the entrails of the West: Multiculturalism, "ethnic food" and migrant homebuilding. In H. Grace, G. Hage, L. Johnson, J. Langsworth, \& M. Symonds (Eds.), Home/World: Communality, identity and marginality in Sydney's West. Sydney: Pluto Press.

Hayes, N. (2010). Doing psychological research: Gathering and analyzing data. Berkshire, UK: Open University Press.

Hubbard, P., \& Kitchin, R. (2010). Introduction: Why key thinkers? In P. Hubbard \& R. Kitchin (Eds.), Key thinkers on space and place (pp. 1-17). London: Sage.

Irannejad, S. (2018). A thousand and one interconnections (Doctoral dissertation, Griffith University).

Jackson, P. (1989). Maps of meaning. London: Routledge.

Jetten, J., Reicher, S. D., Haslam, S. A., \& Cruwys, T. (2020). Together apart: The psychology of Covid-19. London: Sage.

Kyle, G. T., Mowen, A. J., \& Tarrant, M. (2004). Linking place preferences with place meaning: An examination of the relationship between place motivation and place attachment. Journal of Environmental Psychology, 24(4), 439-454.

Lewicka, M. (2005). Ways to make people active: The role of place attachment, cultural capital, and neighborhood ties. Journal of Environmental Psychology, 25(4), 381-395.

Lefebvre, H. (1991). The production of space (Vol. 142). Oxford: Blackwell.

Lefebvre, H. (2006). Critique of everyday life III: From modernity to modernism - Towards a metaphilosophy of the quotidien. London: Verso.

Mandel, R. (2008). Cosmopolitan anxieties: Turkish challenges to citizenship and belonging in Germany. London: Duke University Press.

Medline, A., Hayes, L., Valdez, K., Hayashi, A., Vahedi, F., Capell, W., Sonnenberg, J., Zoe, G., \& Klausner, J. D. (2020). Evaluating the efficacy of stay-at-home orders: Does timing matter? medRxiv. https://doi. org/10.1101/2020.05.30.20117853

Moser, G., \& Uzzell, D. (2003). Environmental psychology. In I. Weiner, T. Millon, \& M. Lerner (Eds.), Handbook of Psychology, Personality and Social Psychology (pp. 419-446). Hoboken, NJ: Wiley \& Sons Inc.

Özet, İ. (2019). Fatih-Başakşehir: Muhafazakar mahallede iktidar ve dönüşen habitus. İstanbul: İletişim.

Primc, K., \& Slabe-Erker, R. (2020). The success of public health measures in Europe during the COVID19 Pandemic. Sustainability, 12(10), 4321.

Prohansky, H. M. (1978). The city and self-identity. Environment and Behavior, 10(2), 147-169. 
Reicher, S. (2000). Against methodolatry: some comments on Elliott, Fischer, and Rennie. British Journal of Clinical Psychology, 39, 1-6.

Rose, G. (1995a). Place and identity: a sense of place. In D. Massey \& P. Jess (Eds.), A place in the world?: Places, cultures and globalization. Oxford: Oxford University Press.

Rose, G. (1995b). Geography and gender, cartographies and corporealities. Progress in Human Geography, 19(4), 544-548. https://doi.org/10.1177/030913259501900407.

Saltiel, F. (2020). Who can work from home in developing countries? Covid Economics, 7, 104-118.

Sayan, S., Krymkowski, D. H., Manning, R. E., Valliere, W. A., \& Rovelstad, E. L. (2013). Cultural influence on crowding norms in outdoor recreation: a comparative analysis of visitors to national parks in Turkey and the United States. Environmental management, 52(2), 493-502.

Sixsmith, J. (1986). The meaning of home: An exploratory study of environmental experience. Journal of Environmental Psychology, 6(4), 281-298.

Silvey, R. (2013). Political moves: Cultural geographies of migration and difference. The Wiley-Blackwell Companion to Cultural Geography, 409-422.

Sorokowska, A., Sorokowski, P., Hilpert, P., Cantarero, K., Frackowiak, T., Ahmadi, K., \& Blumen, S. (2017). Preferred interpersonal distances: A global comparison. Journal of Cross-Cultural Psychology, 48(4), 577-592.

Şenol Cantek, F., Ünlütürk Ulutaş, Ç., \& Çakmak, S. (2014). Evin içindeki sokak, sokağın içindeki ev: Kamusal ile özel "ara”sında kalanlar. In F. Şenol Cantek (Ed.), Kenarın kitabı, (pp. 121-160). İstanbul: İletişim.

Tull, M. T., Edmonds, K. A., Scamaldo, K., Richmond, J. R., Rose, J. P., \& Gratz, K. L. (2020). Psychological outcomes associated with stay-at-home orders and the perceived impact of COVID-19 on daily life. Psychiatry Research, 113098.

van Bavel, J. J. V., Baicker, K., Boggio, P. S. et al. (2020). Using social and behavioural science to support COVID-19 pandemic response. Nature Human Behavior, 4, 460-471. https://doi.org/10.1038/s41562020-0884-Z.

Wood, W. (2000). Attitude change: persuasion and social influence. Annual Review of Psychology, 51, $539-570$.

Woodrow, A. (2001). Why are they laughing? The re-formulation of identity in Canadian stand-up comedy (Doctoral dissertation, Concordia University).

Zick, A. (2010). Psychologie der Akkulturation - Neufassung eines Forschungsbereiches. Wiesbaden. VS.

Zweig, S. (2009). Verwirrung der Gefühle: Erzählungen. S. Fischer Verlag.

Publisher's Note Springer Nature remains neutral with regard to jurisdictional claims in published maps and institutional affiliations. 